\title{
Temporal Changes in Fish Assemblage from the Impingement Data at the Second Nuclear Power Plant,Northern Taiwan
}

\author{
Yun-Chih Liao \\ Research Center for Biodiversity, Academia Sinica, Taipei, Taiwan 115. Institute of Oceanography, National Taiwan \\ University, Taipei, Taiwan 106.
}

Li-Shu Chen

Provisional Office, National Museum of Marine Science and Technology, Keelung, Taiwan 202.

Kwang-Tsao Shao

Research Center for Biodiversity, Academia Sinica, Taipei, Taiwan 115., zoskt@gate.sinica.edu.tw

Yueh-Yuan Tu

Department of Industrial Safety and Environmental Protection, Taiwan Power Company, Taipei, Taiwan 100.

Follow this and additional works at: https://jmstt.ntou.edu.tw/journal

Part of the Terrestrial and Aquatic Ecology Commons

\section{Recommended Citation}

Liao, Yun-Chih; Chen, Li-Shu; Shao, Kwang-Tsao; and Tu, Yueh-Yuan (2004) "Temporal Changes in Fish Assemblage from the Impingement Data at the Second Nuclear Power Plant,Northern Taiwan," Journal of Marine Science and Technology: Vol. 12: Iss. 5, Article 7.

DOI: $10.51400 / 2709-6998.2262$

Available at: https://jmstt.ntou.edu.tw/journal/vol12/iss5/7

This Research Article is brought to you for free and open access by Journal of Marine Science and Technology. It has been accepted for inclusion in Journal of Marine Science and Technology by an authorized editor of Journal of Marine Science and Technology. 


\title{
TEMPORAL CHANGES IN FISH ASSEMBLAGE FROM THE IMPINGEMENT DATA AT THE SECOND NUCLEAR POWER PLANT, NORTHERN TAIWAN
}

\author{
Yun-Chih Liao*,***, Li-Shu Chen**, Kwang-Tsao Shao*, and Yueh-Yuan Tu****
}

Key words: community ecology, fish fauna, fishery resource, fish ecology.

\begin{abstract}
The main purposes of this study are to find out the temporal fluctuation of marine fish community based on impingement data collected at the Second Nuclear Power Plant in recent years (September 2000 to May 2004), and to compare the recent fish community structure data to that of an earlier period, around 14 years ago (July 1987 to April 1990).

Comparison of the data collected recently to that collected 14 years ago showed that there were no yearly or monthly differences. However, the community structures reflected by clustering dendrograms or MDS ordination plots were quite different between earlier and recent years. This difference is likely due to the drastic changes in the dominant species. Fourteen years ago, the most dominant species was mullet (Mugil cephalus), but now, it has changed to lower economic species like rabbitfishes (Siganus fuscescens) and spiny puffer (Diodon holocanthus). This phenomenon might reflect the declination in our fishery resources due to overfishing; a trend especially clear in those species with higher economic values.
\end{abstract}

\section{INTRODUCTION}

The purpose of impingement and entrainment investigation at a power plant is usually to estimate the fishery loss due to cooling water intakes that inevitably impinge fishes or marine organisms larger than the mesh size of the screen $\left(>1 \mathrm{~cm}^{2}\right)$, or entrain eggs or juveniles that are smaller than the mesh size. Moreover, collecting impinged fish specimens is also one efficient and economic way of studying local fish community

Paper Submitted 12/01/04, Accepted 02/22/05. Author for Correspondence: Kwang-Tsao Shao.E-mail: zoskt@gate.sinica.edu.tw.

*Research Center for Biodiversity, Academia Sinica, Taipei, Taiwan 115.

** Provisional Office, National Museum of Marine Science and Technology,

Keelung, Taiwan 202.

***Institute of Oceanography, National Taiwan University, Taipei, Taiwan 106.

****Department of Industrial Safety and Environmental Protection, Taiwan Power Company, Taipei, Taiwan 100. structure, especially pelagic or non-reef associate species which are rarely observed by divers; or non-commercial species that are not usually targeted by traditional fishing methods (Thomas and Miller, 1976; Lifton and Storr, 1978; Rulifson and Copeland 1982; Margraf et al., 1985; Shao and Kuo, 1988; Love et al., 1998; Maes et al., 2001; Hadderingh and Jager, 2002).

In Taiwan, there are three nuclear power plants (NPP), namely the $1^{\text {st }}, 2^{\text {nd }}$ and the $3^{\text {rd }}$ NPP which have been operating since 1977, 1981 and 1984, respectively on northern and southern coasts of Taiwan. The $4^{\text {th }}$ NPP is still in its constructing phase at Yenliao Bay, northeastern coast of Taiwan. Estimation of fishery loss due to impingement and entrainment has been done in previous monitoring or assessment reports (Su et al., 1987, 1988, 1989, Lin, 1990). Shao et al. (1990) have used the impingement data to study the temporal and spatial variation of fish community structures at the three NPPs. They reported that the species composition at the north $1^{\text {st }}$ and $2^{\text {nd }}$ NPP is very different from that of the south $3^{\text {rd }}$ NPP; however, the yearly difference was clear between the $1^{\text {st }}$ and $2^{\text {nd }}$ NPP. The advantages and disadvantages of using impingement data to study fish community structure have also been evaluated (Shao et al., 1990).

The purpose of this study is to examine the temporal fluctuation of marine fish community based on the impingement data collected at the $2^{\text {nd }}$ NPP from September 2000 to May 2004, a recent investigation for three years and 8 months. Secondly to explore possible long term fish community changes after 14 years when a previous investigation took place from July 1987 to April 1990 (Lin, 1990).

\section{MATERIALS AND METHODS}

The impingement fish specimens were collected from the cooling water intake of the $2^{\text {nd }}$ NPP located at Kuosheng (25.20 N, 121.67 E), near Yehliu, northern 
coast of Taiwan. The average generating capacity and the combined water flow velocity of the $2^{\text {nd }} \mathrm{NPP}$ is 980 $\times 2 \mathrm{MW} /$ hour and $1.271 \times 10^{6} \mathrm{gal} / \mathrm{min}$. The geographical feature of the intake of the $2^{\text {nd }}$ NPP is located inside a bay with a small intake mouth which will let the fishes in to be trapped and impinged more easily than the $1^{\text {st }}$ and the $3^{\text {rd }}$ NPP. The substrata at the intake structure of the $2^{\text {nd }}$ NPP are fringe reefs along the shoreline which change into sandy bottom outward about 100-200 m away. Each fish specimen collection took 24 hours using systematic sampling method (Cochran, 1977), i.e. once (from 9 A.M. to the next day at 9 A.M.) monthly from September 2000 to May 2004, a total of 45 months. The impinged fishes on the finest mesh $\left(1 \mathrm{~cm}^{2}\right)$ were flushed into sluice-way and then accumulated in a trash basket suspended outside the pumping house. All fishes present in the trash baskets were collected and brought back to the laboratory for sorting, identification, counting and weighting.

To understand long term community change, earlier impingement data by Lin (1990) from July 1987 to April 1990 (34 months in total), when two collections were made each month (but only once in June 1988), were used to do further comparisons. Due to the fact that earlier investigation showed no raw data but only categorized data, i.e. rare $(R, n=1)$, occasional $(O, n=$ 2-19), common ( $C, n=20-300)$, and abundant $(A, n>$ 300 ); our data with individual numbers had to be converted as multistate data, i.e. 0 for rare, 1 for occasional, 2 for common, and 3 for abundant before doing the multivariate statistics in PRIMER v.5.2.2 (Clarke and Gorley, 2001). For clustering analysis, Bray-Curtis similarity coefficient and UPGMA method were used to construct dendrograms.

For ordination plot, MDS was used then one way ANOSIM was adopted to test whether the communities have changes between two investigations, different years, and seasons. Similarity Percentage (species contribution), as detected by SIMPER, was used to identify which species typified the collective ichthyofaunal compositions between early and recent years. In addition, species number, individual number, and Shannon-Wiener diversity index were calculated for all samplings.

\section{RESULTS AND DISCUSSION}

During recent data collection, from September 2000 to May 2004, a total number of 9,735 individuals belonging to 55 families, 123 genera, and 196 species were collected. The total biomass was $242.2 \mathrm{~kg}$ and the monthly average weight was $5.4 \mathrm{~kg}$. It is difficult to make a fair comparison between recent and earlier fish assemblage data because their sampling times were different and in this case the original data containing individual number of each sample in the earlier years from 1987-1990 could not be retrieved. Although the total sampling times during 1987-1990 (67 times in 34 months, twice each month) was greater than that of the 2000-2004 samplings (45 times in 45 months, once per month), the total number of genus, species, and individual of impinged fishes were found to be higher in this recent years in 2000-2004 than in earlier years in 19871990 (105 genera, 164 species, and 8,258 individuals). On the contrary, the number of different family in the earlier years, 59 families, is slightly higher than the 55 collected in the recent years.

The most abundant species and their individual number listed in order were Siganus fuscescens $(6,124)$, Diodon holocanthus $(1,920)$, Sardinella gibbosa $(233)$, Abudefduf vaigiensis (181), Balistoides viridescens (76), Sardinella lemura (68), Trachurus japonicus (64), Hypoatherina woodwardi (54), and Pempheris oualensis (43). The most frequent occurring species were $D$. holancanthus, A. vaigiensis, $S$. fuscencens, $H$. woodwardi, Pempheris oualensis, Abudefduf bengalensis, S. gibbosa, Trichurus lepturus, Apogon doederleini, Alectic ciliaris, and Tylosurus crocodiles. Similarity Percentage (species contribution), as detected by SIMPER, from the $50 \%$ cumulative percentage for 17 species also shows the same result (Table 1). The most dominant species in earlier years used to be Mullet (Mugil cephalus) which has very high economic value; but in recent years, lower values species including rabbitfish (S. fuscescens) and spiny puffer (D. holocanthus) have became the dominant species. This result indicates and points out the problem of overfishing mullets in past 10 years. The total number of mullets caught annually in Taiwan has dropped from more than 100 million individuals to less than 0.1 million individuals in the past few years (Hwang et al., 2003). Beside that, the fish assemblages were influenced by the dominant species much more in recent years than that in early years.

Figure 1 demonstrates the monthly variation of species number at two different time periods. After excluding those data with unusual high species number, during September and October 1988 (46 and 48 species) and July and August 1989 (44 and 33 species), seasonal fluctuation of species number showed peaks in JulySeptember and dips in March-April in both the earlier and the recent years. Figure 2 shows monthly variation of individual number, and several peaks in March 2002 (619 individuals), June $(3,141)$, July $(1,524)$, and August (688) 2003 which were mainly caused by seasonal massive impingement of dominant species, such as $D$. holocanthus (March-April), and S. fuscescens (JuneAugust). For example, a lot of juveniles or young fishes 
Table 1. Similarity Percentage (species contributions), as detected by SIMPER, from fish communities at the $2^{\text {nd }}$ NPP, north Taiwan, between earlier years (1987-1990) and recent years $(2000-2004)$

\begin{tabular}{|c|c|c|c|c|c|c|}
\hline \multirow[b]{2}{*}{ Species } & $1987-1990$ & $2000-2004$ & \multirow[b]{2}{*}{ Av. Diss } & \multirow[b]{2}{*}{ Diss/SD } & \multirow[b]{2}{*}{ Contrib\% } & \multirow[b]{2}{*}{ Cum.\% } \\
\hline & Av. Abund & Av. Abund & & & & \\
\hline Mugil cephalus & 1.94 & 0.09 & 4.25 & 1.26 & 5.55 & 5.55 \\
\hline Diodon holocanthus & 1.65 & 2.67 & 3.71 & 1.30 & 4.85 & 10.40 \\
\hline Hypoatherina woodwardi & 1.59 & 0.71 & 3.18 & 1.06 & 4.15 & 14.55 \\
\hline Siganus fuscescens & 0.24 & 1.24 & 2.91 & 1.16 & 3.80 & 18.35 \\
\hline Trichiurus lepturus & 1.29 & 0.53 & 2.85 & 1.01 & 3.73 & 22.07 \\
\hline Pempheris oualensis & 1.12 & 0.71 & 2.53 & 0.93 & 3.30 & 25.37 \\
\hline Abudefduf vaigiensis & 1.91 & 1.38 & 2.48 & 0.76 & 3.24 & 28.62 \\
\hline Abudefduf sexfasciatus & 1.00 & 0.04 & 2.28 & 0.93 & 2.98 & 31.60 \\
\hline Alectis ciliaris & 0.59 & 0.49 & 1.96 & 0.81 & 2.56 & 34.16 \\
\hline Abudefduf bengalensis & 0.53 & 0.67 & 1.96 & 0.79 & 2.56 & 36.71 \\
\hline Pomacentrus coelestis & 0.74 & 0.13 & 1.73 & 0.87 & 2.26 & 38.97 \\
\hline Sardinella sindensis & 0.82 & 0.00 & 1.70 & 0.65 & 2.23 & 41.20 \\
\hline Engraulis japonica & 0.62 & 0.07 & 1.62 & 0.57 & 2.12 & 43.31 \\
\hline Tylosurus crocodilus & 0.41 & 0.49 & 1.56 & 0.79 & 2.04 & 45.35 \\
\hline Sardinella gibbosa & 0.00 & 0.62 & 1.40 & 0.63 & 1.83 & 47.19 \\
\hline Apogon doederleini & 0.56 & 0.24 & 1.35 & 0.92 & 1.76 & 48.95 \\
\hline Trachurus japonicus & 0.29 & 0.27 & 1.16 & 0.53 & 1.52 & 50.47 \\
\hline
\end{tabular}

Av. Abund, average abundance; Av. Diss, average dissimilarity; Diss/SD, standard deviation of dissimilarity; Contrib\%, contribution percentage; Cum.\%, cumulative percentage.

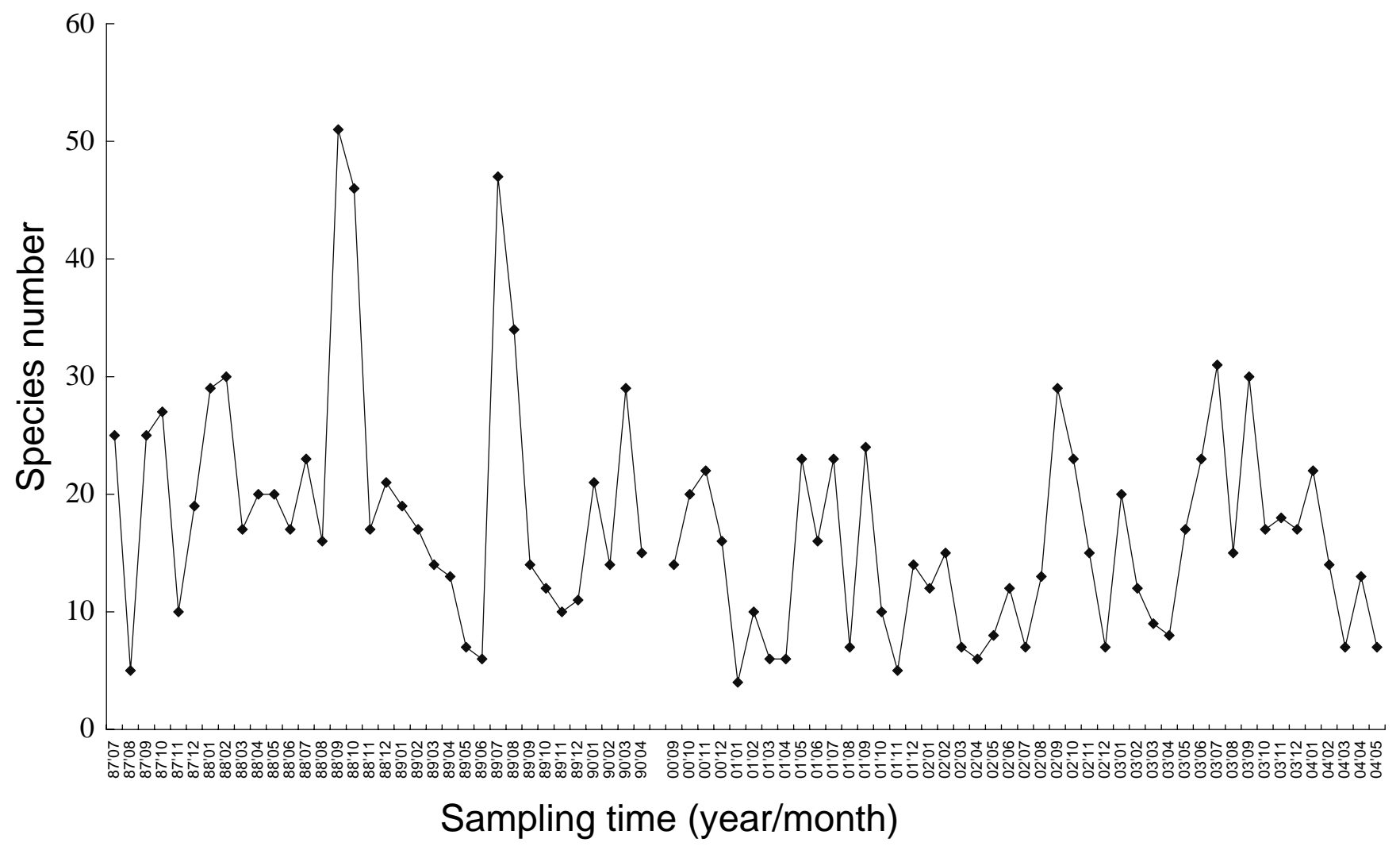

Fig. 1. Monthly variation of impinged fish species number collected at the $2^{\text {nd }}$ NPP in two different periods of time (1987-1990 vs. 2000-2004). 


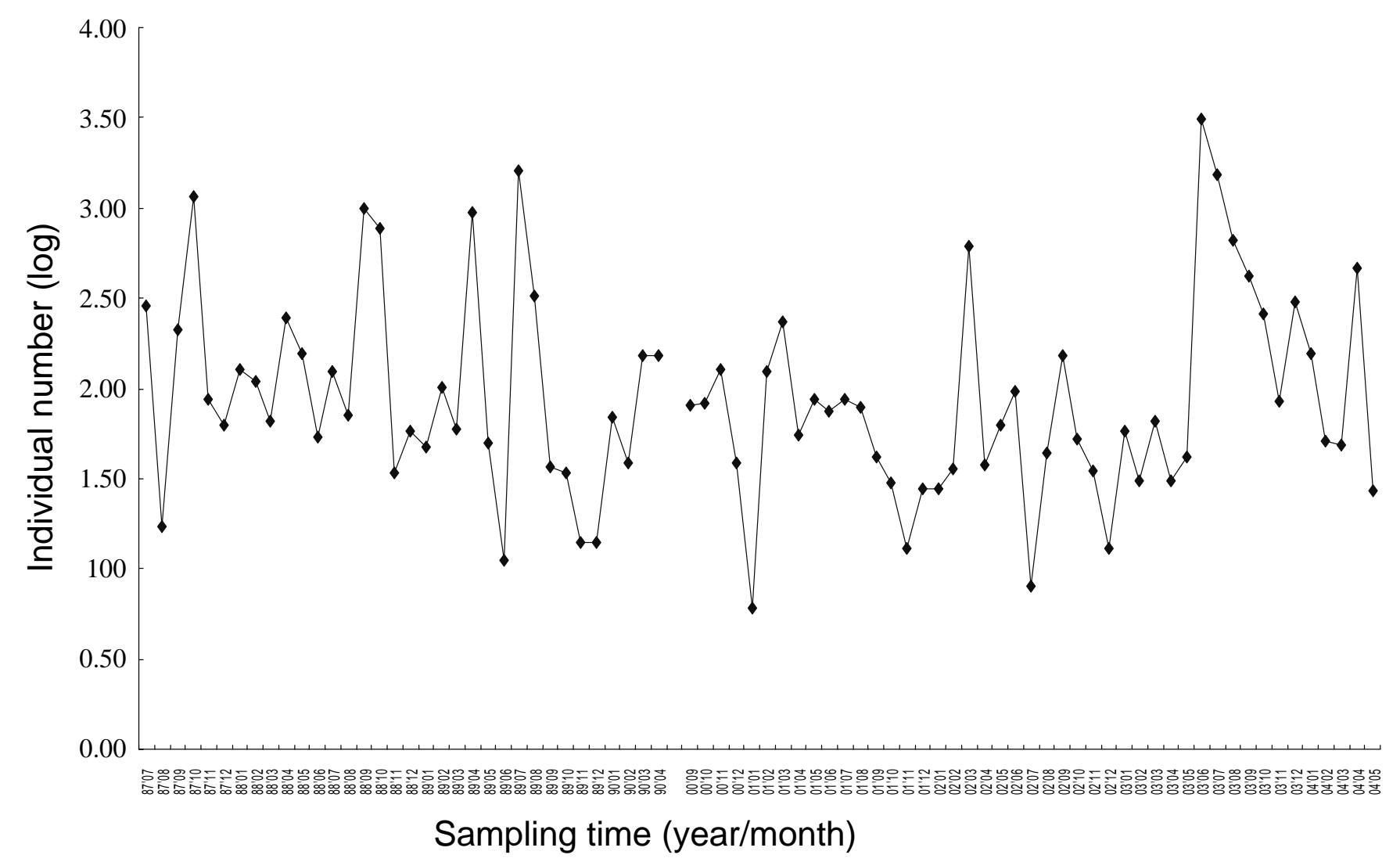

Fig. 2. Monthly variation of impinged individual number collected at the $2^{\text {nd }}$ NPP in two different periods of time (1987-1990 vs. 2000-2004).

of spiny puffer (D. holocanthus; $\mathrm{SL}<10 \mathrm{~cm}$, BW $<120$ g) migrated toward inshore in March and April months could imply that their spawning season is in January or February. Leis (2001) pointed out that D. holocanthus have inshore migratory behavior after their young fishes complete their drifting pelagic stage. Periodically lower values of Shannon-Weiner index in March-April months are likely the result of massive impingement of young spiny puffers during this period of time. After these massive impinged species were detected, the same usual seasonal peak in the summer was detected in individual number as the species number. The Shannon-Weiner diversity index values were $0.28-1.22$ with 0.85 in average for earlier years, and 0.04-1.26 with 0.65 in average for recent years (Figure 3). Similarly, the lowest index values occurred in March-April for both earlier and recent years. The lower values of diversity index and evenness index in the summer accordingly, could be explained. Data of the earlier years conducted, March-April and June-September also showed high individual numbers in addition to that in October 1987, September-October 1988, April and July 1989. The most dominant species during these three years, in respectively, were: $H$. woodwardi, M. cephalus and $A$. vaigiensis in 1987; Engraulis japonica and M. cephalus in 1988; and M. cephalus and S. sindensis in 1989. Therefore, annual dual peaks in early spring and summer for individual number of coastal fishes exist in northern Taiwan.

Clustering analysis results tell us that the fish assemblages between recent years (2000-2004) and earlier years (1987-1990) are obviously different, including their similarity values within each collection. Figure 4 clearly demonstrate the differences in fish assemblages found in earlier (1987-1990) and recent (20002004) years. Figure 5 is the UPGMA dendrograms for the 2000-2004 impingement data. Although there are no clear monthly or yearly differences, seasonal groups have been observed: 1. Summer-autumn group (G1): mainly from June 2003 till January 2004, dominanted by rabbitfish (S. fuscescens), with 54-3,098 individuals that comprised $64-99 \%$ of the total individual collected in those months. 2. Winter-spring group (G2): mainly composed of large number of spiny puffer $(D$. holocanthus), with 106-612 individuals which comprised 86-99 \% of the total number. 3. Autumn group (G3): contained samples with lower similarity values among them $(<50 \%)$. 


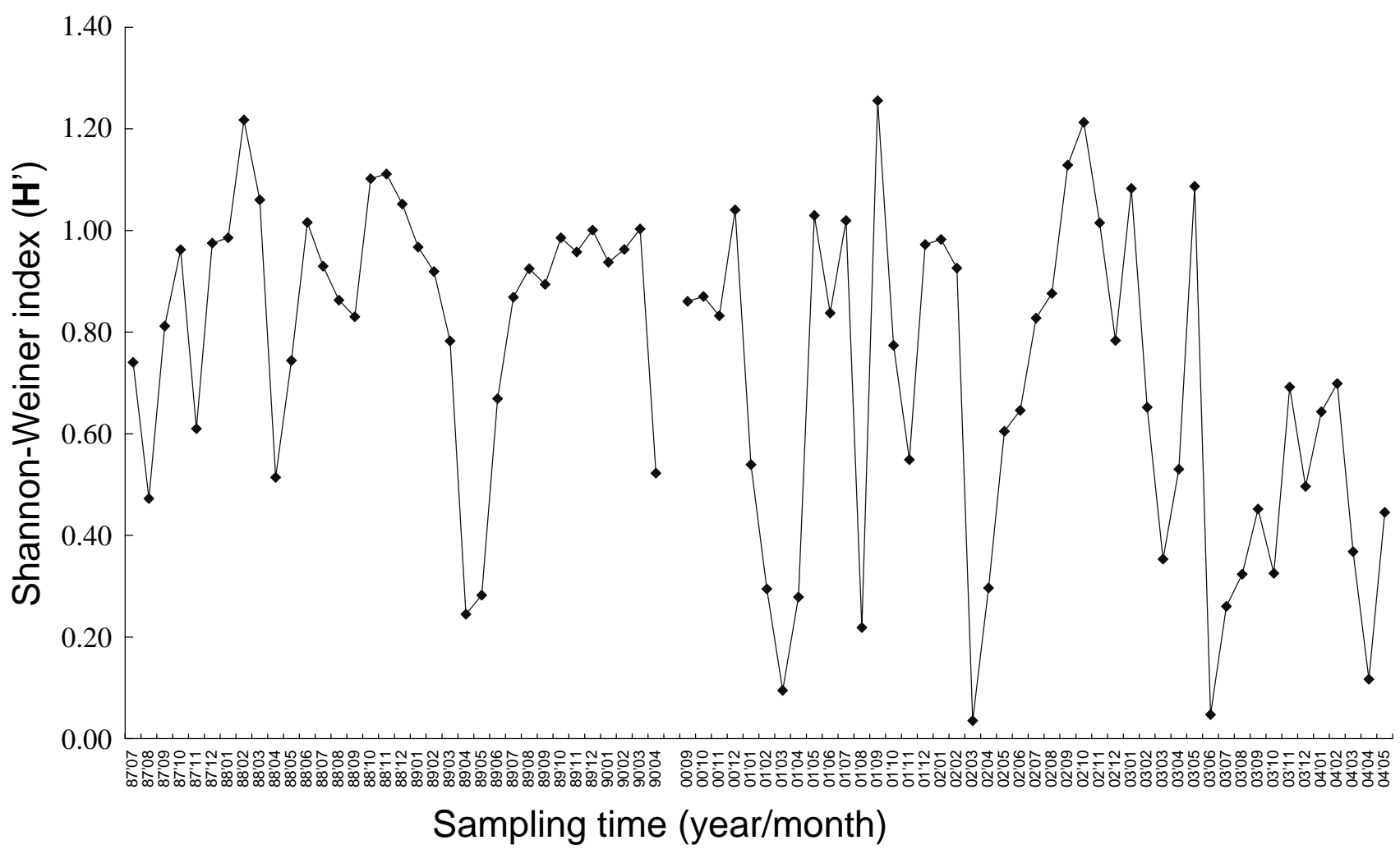

Fig. 3. Monthly variation of Shannon-Weiner index (H') of fishes impinged at the $2^{\text {nd }}$ NPP in two different periods of time (1987-1990 vs. 2000-2004).

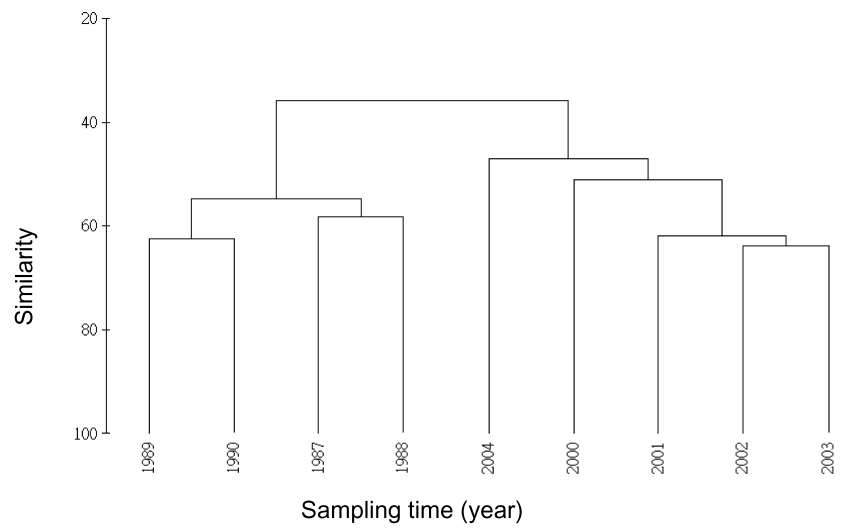

Fig. 4. UPGMA dendrogram of impinged fish assemblages at the $2^{\text {nd }}$ NPP between earlier years (1987-1990) and the recent years (2000-2004).

Figure 6 shows the MDS ordination plot of temporal variation of impinged fish assemblage. There are clear differences $(R=0.492, P=0.001)$ between the two different time frames using one-way ANOSIM test. In the earlier years, the dispersion index was 0.892, which is smaller than 1.061 of the recent years. This indicates that the variation in species composition is much greater

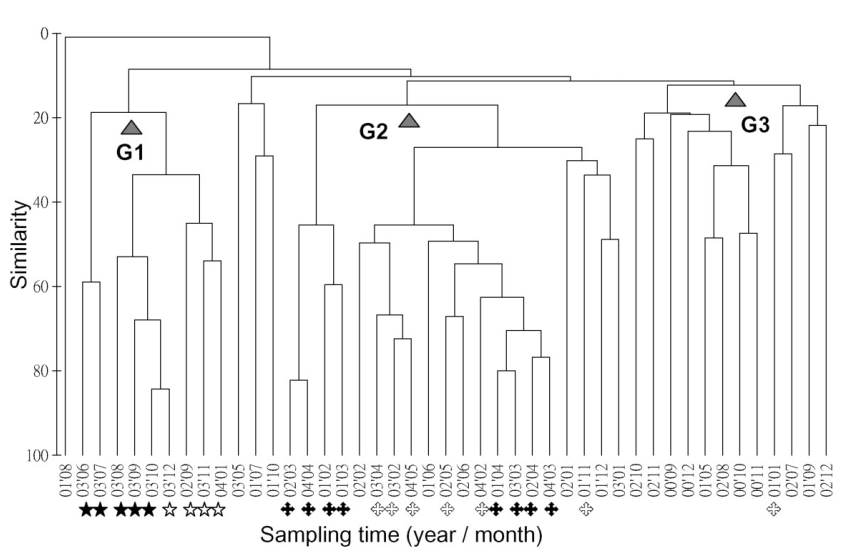

Fig. 5. UPGMA dendrogram of the impingement fish assemblages at the $2^{\text {nd }}$ NPP during 2000-2004. 5 indicates fish assemblage was dominant by rabbitfish in that month, and indicates spiny puffer. Solid mark and open mark means that the total number of individual exceeds $75 \%$ and $50-75 \%$, respectively.

in the present compared to 14 years ago. There is no significant yearly difference in the MDS plot. Statistical test, one-way ANOSIM, shows that result had no significant differences $(R=0.374, P=0.001)$. There is no monthly difference or trends to be found on the MDS 
plot, either. And statistical test of one-way ANOSIM does not show any significant difference as well $(R=$ $0.119, P=0.001)$.

The ascending trend of the species cumulative curve of the investigations from 1987-1990 and 20002004 , suggests that the species number will still continue to increase in the further samplings (Figure 7).

Figure 8 is the dominance curve of the impingement fishes based on the individual number collected at the $2^{\text {nd }}$ NPP during 2000-2004. This curve shows that

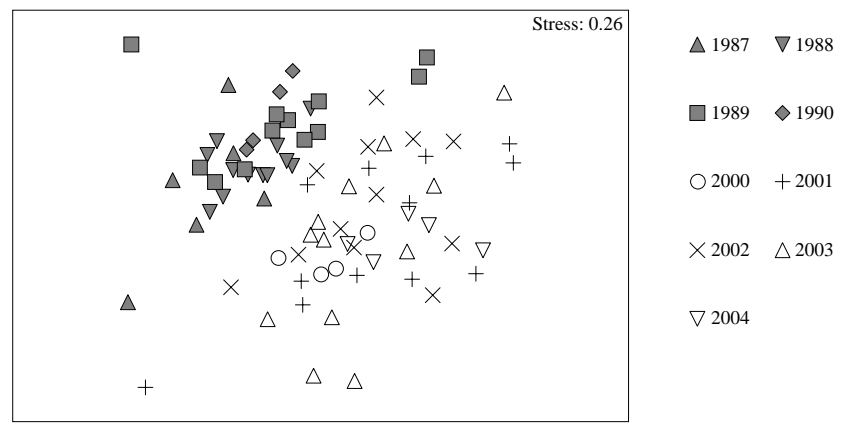

Fig. 6. MDS ordination for temporal (yearly) variation of impingement fish assemblages at the $2^{\text {nd }} \mathrm{NPP}$. the most dominant species could make up more than $50 \%$ of the total individual numbers in 2001-2004, and even up to $90 \%$ in 2003 .

In conclusion, the fish assemblage structure in both the recent (2000-2004) and the earlier (1987-1990) years could not reveal significant small-scale temporal (monthly or yearly) variations. However, if we com-

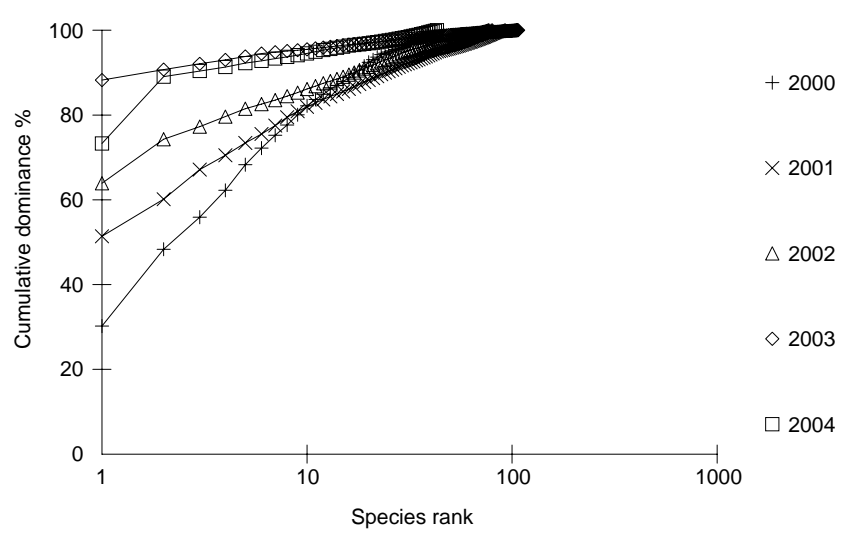

Fig. 8. Cumulative dominance curve of the impingement fishes based on the individual numbers collected at the $2^{\text {nd }}$ NPP during 20002004.

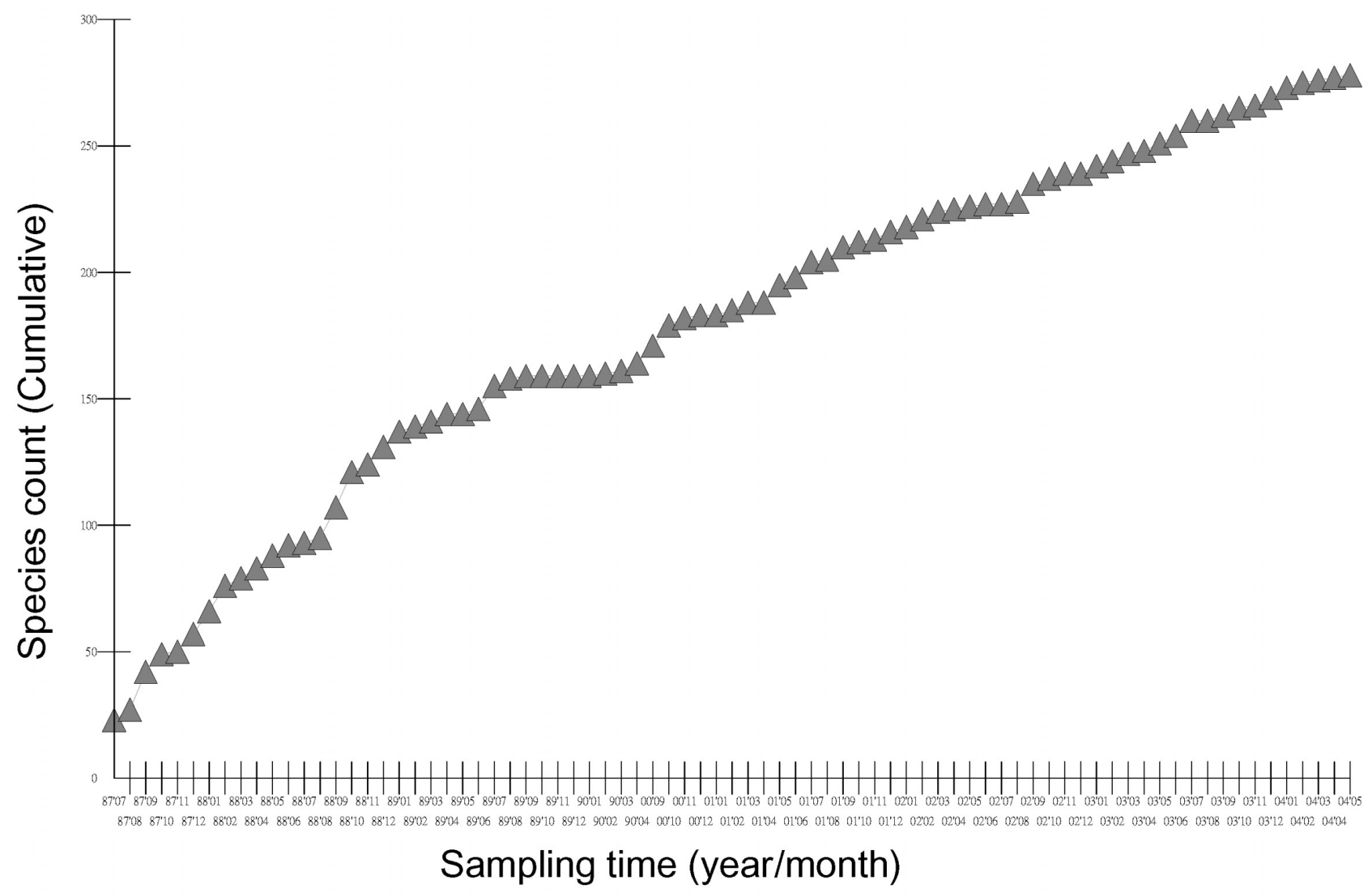

Fig. 7. Species cumulative curve of the impingement fishes at the $2^{\text {nd }}$ NPP. 
pare the assemblages between the two time periods, i.e. a large-scale, on a long term basis of 10-14 years, the species composition has become significantly different. The result indicates that the community ecological monitoring needs to be continued for at least 10 years or longer.

\section{REFERENCES}

1. Clarke, K.R. and Gorley, R.N., "PRIMER. V5.2.2: User Manual/Tutorial, PRIMER-E," Plymouth, UK, pp. 1-91 (2001).

2. Cochran, W.G., "Comparison and Prediction of Fish Impingement Rates at Power Plant Cooling Water Intake Sites," Proceedings of the Third National Workshop on the Entrainment and Impingement, Ecological Analysis. Inc., Melville, N.Y., pp. 255-267 (1977).

3. Hadderingh, R.H. and Jager, Z., "Comparison of Fish Impingement by a Thermal Power Station with Fish Population in the Ems Estuary," J. Fish Biol., Vol. 61, Supl. A, pp. 105-124 (2002).

4. Hwang, C.S., Xie, S.S., Wu, C.C., Wu, L.J., Lin, J.C., and Su, W.C., "Investigation and Monitor of Mullet Fish (Mugil Cephalus) off Taiwan," FRI Newsletter, Vol. 2, pp. 21-23 (2003) (in Chinese).

5. Leis, J.M., "Diodontidae. Porcupine Fishes (Burrfishes)," K.E., Carpenter and Niem, V., (eds.) FAO Species Identification Guide for Fishery Purposes, The Living Marine Resources of the Western Central Pacific. Carpenter, K.E. and Niem, V. (Eds.), FAO, Rome, Vol. 6. Bony Fishes Part 4, pp. 3958-3965 (2001).

6. Lifton, W.S. and Storr, J.F., "The Effect of Environmental Variables on Fish Impingement," Proceedings of the Fourth National Workshop on the Entrainment and Impingement. Jensen, L.D. (Ed.), Ecological Analysis. Inc., Melville, N.Y., pp. 299-311 (1978).

7. Lin, J.P., "Analysis on the Fish Communities in the Northern and Southern Coastal Waters of Taiwan by Using Impingement Data," Master Thesis, Institute of Fisheries, National Taiwan University, Taipei, Taiwan (1990).

8. Love, M.S., Caselle, J.E., and Herbinson, K., "Declines in Nearshore Rockfish Recruitment and Populations in the Southern California Bight as Measured by Impingement rates in Coastal Electrical Power Generating Stations," Fish. Bull., Vol. 96, No. 3, pp. $492-501$ (1998).
9. Maes, J., Pas, J., Taillieu, A, Van Damme, P.A., and Ollevier, F., "Sampling of Fish and Crustaceans at the Cooling Water Intake of an Estuarine Power Plant: a Comparison with Stow Net Fishery," Arch. Fish. Mar. Res., Vol. 49, No. 1, pp. 27-36 (2001).

10. Margraf, F.J., Chase, D.M., and Strawn, H., "Intakes Screens for Sampling Fish Populations: the Size-Selectivity Problem," North Amer. J. Fish. Manag., Vol. 5, pp. 210-213 (1985).

11. Rulifson, R.A., and Copeland, B.J., "Traveling Screens as Sampling Gear Fir Vertical Distribution Studies," Estuarines, Vol. 5, pp. 82-94 (1982).

12. Shao, K.T. and Kuo, S.R., "Species Composition and Seasonal Distribution of Impinged Fishes at the Two Intakes Along the Northern Coast of Taiwan," Acta. Zool. Taiwan, Vol. 2, pp. 209-227 (1988).

13. Shao, K.T., Lin, C.P., Ho, L.T., and Lin, P.L., "Study on the Fish Communities from Northern and Southern Waters of Taiwan by Analyzing the Impingement Data," J. Fish. Soc. Taiwan, Vol. 17, No. 2, pp. 73-90 (1990).

14. Su, C.C., Hong, S.C., Jang, T.C., Tan, T.C., Chang, K.H., Shao, K.T., Hwang, P.P., Lee, K.T., Hwang, J.T., Hwang, C.U., Fun, K.L., and Yeh, T.Y., “An Ecological Survey on the Waters Adjacent to the Southern Taiwan Nuclear Power Plant Sites," Spec. Publ. NSCOPE, Vol. 49, pp. 1134 (1987).

15. Su, C.C., Hong, S.C., Jang, T.C., Tan, T.C., Chang, K.H., Shao, K.T., Hwang, P.P., Lee, K.T., Hwang, J.T., Hwang, C.U., Fun, K.L., and Yeh, T.Y., "An Ecological Survey on the Waters Adjacent to the Southern Taiwan Nuclear Power Plant Sites," Spec. Publ. NSCOPE, Vol. 58, pp. 1281 (1988).

16. Su, C.C., Hong, S.C., Jang, T.C., Tan, T.C., Chang, K.H., Shao, K.T., Hwang, P.P., Lee, K.T., Hwang, J.T., Hwang, C.U., Fun, K.L., and Yeh, T.Y., "An Ecological Survey on the Waters Adjacent to the Southern Taiwan Nuclear Power Plant Sites," Spec. Publ. NSCOPE, Vol. 69, pp. 1258 (1989).

17. Thomas, D.L. and Miller, G.J., "Impingement Studies at the Oyster Creek Generation Station, Fork River, New Jersey, from September to December 1975," Proceedings of the Fourth National Workshop on the Entrainment and Impingement. Jensen, L.D. (Ed.), Ecological Analysis. Inc. Melville, N.Y., pp. 317-341 (1976). 